\title{
A polymorph bactericidal defect and a lupus-like syndrome
}

\author{
R J LEVINSKY, B A M HARVEY, D M ROBERTON, AND O H WOLFF \\ Institute of Child Health, London
}

SUMMARY We describe a child with a primary defect of polymorph bacterial killing associated with systemic lupus erythematosus. We suggest that her autoimmune disease results from chronic bacterial antigen stimulation and propose a hypothetical model linking immunodeficiency with autoimmunity.

The clearance of antigens from the circulation is a function of the antibody, complement, and phagocyte pathways. Defective antigen clearance is thought to underlie the development of immune complex disease and, indeed, there are many associations between primary deficiencies of these immunity functions and presumed immune complex diseases. These include selective IgA deficiency and juvenile chronic polyarthritis, ${ }^{1}$ homozygous $\mathrm{C} 2$ deficiency, and such diseases as systemic lupus erythematosus (SLE) and Henoch-Schönlein purpura, ${ }^{2}$ as well as a similar predisposition with the much rarer complement deficiencies of $\mathrm{Clr}, \mathrm{Cls}$, and $\mathrm{C} 4 .^{3}$ No primary abnormalities of macrophage function have been described, but the mothers of children with chronic granulomatous disease (CGD), an X-linked recessive condition in which there is a deficiency of polymorph bactericidal activity, have an increased prevalence of discoid lupus. ${ }^{4}$ We describe a girl with many features of SLE, in whom we found a primary defect of bacterial killing by her polymorphs.

\section{Case history}

An 8-year-old girl presented with a history of a photosensitive skin rash affecting the malar area of her face since 2 years of age. During the preceding 2 years she had also had persistent lumps like 'chilblains' on the toes and heels of both feet, and on both index fingers. She also complained of frequent small skin lesions on her face and limbs. These started as raised red lumps which invariably broke down and became infected with staphylococci. There was minor scarring upon healing. She had had frequent mouth ulcers for several years and recently had complained of increasing tiredness and lethargy. On examination she had a rash on her face typical of lupus, 'chilblain'-like lesions on fingers, heels, and toes, and numerous vasculitic lesions on her arms and legs, and on her nose. Several of these vasculitic lesions were infected. Her spleen was easily palpable. Relevant investigations showed anaemia with a raised erythrocyte sedimentation rate, lymphopenia, raised immunoglobulins, positive rheumatoid factor $(1: 60)$, raised antinuclear antibody titre $(1: 40)$, high levels of IgG immune complexes, but only slightly raised anti-DNA antibody levels. Polymorph function testing showed abnormal nitroblue tetrazolium (NBT) reduction, defective bactericidal activity for Staphylococcus aureus, and a reduced neutrophil iodination response to $S$. aureus and yeast. She had normal total haemolytic and C3 complement levels and no proteinuria or haematuria. Urinary porphyrins were also normal. She was treated with continuous Septrin and barrier creams and during the next 2 months the disease remitted and results of tests returned to normal except those of polymorph function. During the early summer she had an exacerbation and on that occasion responded fully to a short course of chloroquine. She remains well on prophylactic Septrin.

\section{Subjects}

The family we studied consisted of the father, mother, unaffected older sister, and the patient. Five children with SLE with various degrees of disease activity and drug treatment were studied too. In addition, during the last 5 years, we have performed neutrophil function tests on 10 children with CGD and on their mothers. Control values on 10 healthy adults are also included.

\section{Methods}

Stimulated nitroblue tetrazolium test. ${ }^{5}$ This test gives a crude measurement of the oxidative metabolic pathways concerned in bacterial killing by polymorphs. Escherichia coli $(20 \mu \mathrm{g})$ endotoxin was 
added to $0 \cdot 2 \mathrm{ml}$ whole blood in EDTA in the presence of $0.2 \%$ NBT. After incubation, a blood smear was stained and the percentage of neutrophils showing black deposits of the reduced formazan dye in the cytoplasm was counted.

Bactericidal test. Neutrophils were separated from fresh heparinised blood by dextran sedimentation. The washed neutrophils were resuspended in Hanks's balanced salt solution without antibiotics and then mixed with a washed overnight broth culture of the Oxford strain of $S$. aureus at a ratio of 10 organisms to 1 neutrophil in the presence of $8 \%$ fresh normal serum. After 20 minutes' incubation at $37^{\circ} \mathrm{C}$, the cells were sedimented and the supernatant containing any unphagocytosed organisms was removed. The cell deposit was then resuspended in Hanks's solution, to which gentamicin had been added, and an aliquot removed. The remainder was incubated for a further 2 hours after which a second aliquot was removed. Both aliquots were washed, the cells disrupted in distilled water, and the viable intracellular organisms cultured overnight in pour plates. The number of viable organisms at 140 minutes divided by the number at 20 minutes gives the bactericidal index. Normal values are below $0 \cdot 11$.

Neutrophil iodination response. During the process of microbial killing by neutrophils, halide ions become protein incorporated by covalent bonding with receptors such as tyrosine; this reaction appears to be peroxidase-dependent. Incorporation of radiolabelled iodine by phagocytosing neutrophils can be used to assess the oxidative response towards different organisms. Neutrophil iodination was assessed by a microtitre plate modification of the method of Pincus and Klebanoff 6 using bakers yeast and $S$. aureus as the phagocytic particles. Washed dextran-separated neutrophils were adjusted to a concentration of $5 \mathrm{million} / \mathrm{ml}$. This suspension $(50 \mu \mathrm{l})$ was added to duplicate wells of Limbro Titertek microtitre plates containing $50 \mu \mathrm{l}$ glucosephosphate buffer, $0.08 \mu \mathrm{Ci}^{125} \mathrm{I}, 50 \mu \mathrm{l}$ standardised yeast suspension (Saccharomyces cerevisiae), and $25 \mu \mathrm{l}$ of homologous human serum diluted to give a final serum concentration of $1.5 \%$. The plates were incubated at $37^{\circ} \mathrm{C}$ for 1 hour, after which the cells were harvested on to Whatman fibreglass filter papers with a Titertek multichannel cell harvester. The fibreglass discs were dried and counted in a Wallac gamma counter. The iodination response to $S$. aureus was tested under similar assay conditions, but the neutrophil number and serum concentration were double those used for yeast iodination. Results were expressed as a percentage of the responses obtained for healthy adult controls tested simultaneously.

\section{Results}

Stimulated NBT. These are shown in Fig. 1. The normal range (mean $31 \cdot 2 \pm 16 \cdot 7 \% 2 \mathrm{SD}$ ) of 10 healthy control subjects is given. In the father and sister, and in the 2 patients with SLE tested, results were high or normal, but in the mother the result was in the low to normal range. The patient on three separate occasions gave results that were similar to those obtained in CGD carriers. CGD patients did not show any NBT-positive cells.

Bactericidal index. These are shown in Fig. 2. Normal values for the 10 control subjects (log mean \pm 2 SD) are shown with all the values obtained from CGD patients being above this range and the carrier mothers giving high but intermediate values. The patient's neutrophils showed defective bacterial killing on three separate occasions, while the rest of her family and the 5 children with SLE gave normal values.

Neutrophil iodination response. Two control subjects tested at the same time as the patient and her mother gave iodination responses of 121 and $81 \%$ of the mean response obtained for neutrophils from 10 healthy donors tested (with yeast) under the same assay conditions and with the same homologous serum on 22 occasions (mean response \pm SD $=20 \cdot 851 \pm 4744$ counts $/ \mathrm{min}$ ).

The results of staphylococcal and yeast iodination responses of the mother's and the patient's neutrophils are shown in the Table. In both tests the

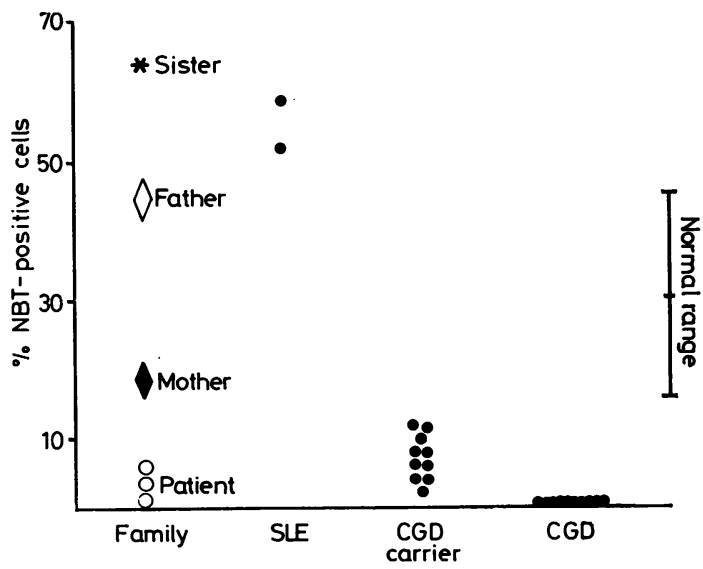

SLE = systemic lupus erythematosus $; C G D=$ chronic granulomatous disease;

Normal range, mean \pm 2 SD.

Fig. 1 Nitroblue tetrazolium dye reduction in polymorphs stimulated with Escherichia coli endotoxin. 


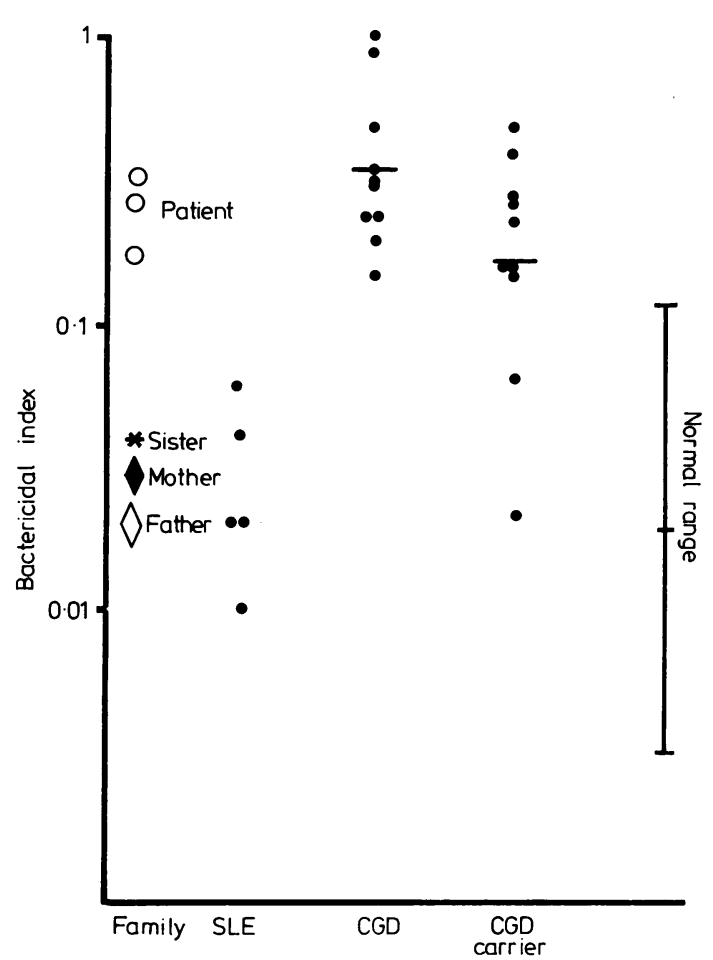

Fig. 2 Polymorph bactericidal activity against Staphylococcus aureus expressed as bactericidal index.

Table Neutrophil iodination response

\begin{tabular}{|c|c|c|c|c|}
\hline & \multicolumn{2}{|c|}{ Yeast iodination } & \multicolumn{2}{|c|}{$\begin{array}{l}\text { Staphylococcus aureus } \\
\text { iodination }\end{array}$} \\
\hline & Counts/min & $\begin{array}{l}\% \text { of mean } \\
\text { control } \\
\text { response }\end{array}$ & Counts/min & $\begin{array}{l}\% \text { of mean } \\
\text { control } \\
\text { response }\end{array}$ \\
\hline $\begin{array}{l}\text { Mother } \\
\text { Patient }\end{array}$ & $\begin{array}{r}17414 \\
7342\end{array}$ & $\begin{array}{l}80 \cdot 0 \\
33 \cdot 8\end{array}$ & $\begin{array}{r}2309 \\
613\end{array}$ & $\begin{array}{l}84 \cdot 2 \\
22 \cdot 4\end{array}$ \\
\hline
\end{tabular}

patient's neutrophils gave defective iodination, but those of her mother responded normally.

The patient's serum did not alter the iodination responses of the two controls, indicating that the defect was not due to a serum inhibitor.

\section{Discussion}

CGD is an X-linked recessive condition, in which the neutrophils of affected patients fail to kill bacteria-such as staphylococci, klebsiella, E. coli, and Serratia marcescens-or moulds-such as Aspergillus sp. or Nocardia sp. ${ }^{4}$ Most of the children have repeated bacterial or fungal infections and many die before reaching adult life. Their mothers also have a defect in polymorph bacterial killing, yet do not have an increased prevalence of similar infections. However, the mothers do appear to have a predisposition to immune complex diseases since in a study of 10 children with CGD, 2 of the mothers had discoid lupus and one had polyarthritis and Raynaud's phenomenon. ${ }^{4}$

Our results of polymorph function testing in this family show the defect only in the index patient. Females with phenotypic CGD and presumed autosomal recessive inheritance have been described, ${ }^{7}$ but this child's illness does not fall into that category. It is probable that she is a carrier for CGD, and if so, the genetic defect must have occurred by new mutation. Her illness of mild SLE, coupled with frequent infections as a result of the polymorph bacterial killing defect, illustrates the close association of an immunodeficiency involving antigen clearance and an immune complex disease. While most patients with SLE do not have demonstrable primary immunodeficiencies, the association of deficiencies in man of antibody, ${ }^{1}$ complement components, ${ }^{23}$ and now neutrophil function with immune complex diseases argues in favour of immunodeficiency being of primary importance in their development. $\dot{A}$ failure to cope with repeated bacterial infections as in this child, would lead to chronic antigenic stimulation. The hypothetical model for the development of an autoimmune disease by polyclonal B-lymphocyte stimulation is shown in Fig. 3. Such polyclonal stimulation leads to autoantibody responses, such as rheumatoid factors and antinuclear antibodies. An animal experimental model for this has been produced in mice in which an SLE-like condition, with autoantibody production, can be induced by intravenous injection of the polyclonal B-cell stimulator, bacterial lipopolysaccharide. ${ }^{8}$ Furthermore, in human disease, antiDNA antibodies may be found in cryoprecipitates

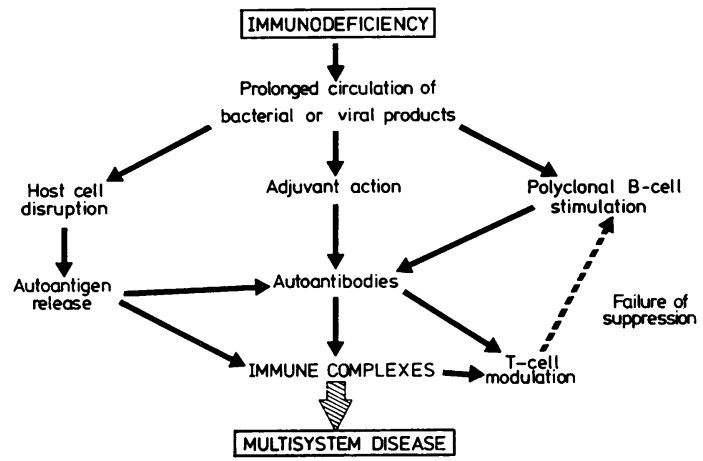

Fig. 3 Hypothetical model for association of immunodeficiency and autoimmune complex disease. 
obtained not only from patients with SLE, but also from patients with prolonged bacterial infections such as subacute bacterial endocarditis. ${ }^{9}$

It is of interest that this child's illness could be controlled by prevention of bacterial infections with prophylactic Septrin. Thus by reducing antigenic stimulation, the autoantibody response was diminished. This experience differs from that seen in the majority of patients with SLE in whom antibody suppression by means of steroids or cytotoxic drugs is generally necessary. In such patients the sustained failure of antibody regulation could be due to abnormalities of T-cell suppressor function since such abnormalities have been demonstrated in families of patients with SLE, ${ }^{10}$ and also in the NZB/W mouse, a strain particularly prone to develop SLE upon ageing. ${ }^{11}$

These associations of immunodeficiency and immune complex diseases may provide clues to the underlying causes. It is possible that in patients with SLE, other, but still undefined, subtle defects of antigen handling could lead to prolonged B-cell stimulation by viruses or bacteria with the resulting autoantibody production failing to switch off because of a lack of T-cell suppressor function. A primary defect for this suppressor function need not be invoked since immune complexes are known to modulate the immune response and different types may help or suppress lymphocyte function in different circumstances. ${ }^{12}$ Alternatively, such modulation may occur via an anti T-cell antibody, found in certain SLE patients' sera, which recognises a T-cell subset with helper function for immunoglobulin production by B-cells. ${ }^{13}$

\section{References}

1 Cassidy J T, Burt A, Petty R, Sullivan D. Letter: Selective IgA deficiency in connective tissue diseases. $N$ Engl $J$ Med $1969 ; 280$ : 275.
${ }^{2}$ Glass D, Raum D, Gibson D, Stillman J S, Schur P H. Inherited deficiency of the second component of complement. Rheumatic disease associations. J Clin Invest 1976; 58: 853-61.

3 Agnello J. Complement deficiency states. Medicine (Baltimore) 1978; 57: 1-23.

4 Thompson E N, Soothill J F. Chronic granulomatous disease; quantitative clinicopathological relationships. Arch Dis Child 1970; 45: 24-32.

5 Park B H, Good R A. Letter: NBT test stimulated. Lancet 1970; ii: 616.

${ }^{6}$ Pincus S H, Klebanoff S J. Quantitative leucocyte iodination. N Engl J Med 1971; 284: 744-50.

7 Quie P G, Kaplan E L, Page A R, Gruskay F L, Malawista S E. Defective polymorphonuclear leucocyte function and chronic granulomatous disease in two female children. N Engl J Med 1968; 278: 976-80.

8 Izui S, Lambert P H, Fournie G J, Turler H, Miescher P A. Features of systemic lupus erythematosus in mice injected with bacterial lypopolysaccharides. Identification of circulating DNA and renal localisation of DNA/antiDNA complexes. J Exp Med 1976; 145: 1115-30.

9 Lewis E J, Roberts J L. Hypothesis. Is autoimmunity a common denominator in immune complex diseases? Lancet 1980 ; i: 178-80.

10 Miller K B, Schwartz R S. Familial abnormalities of suppressor cell function in systemic lupus erythematosus. N Engl J Med 1979; 301 : 803-9.

11 Krakauer R S, Waldmann T A, Strober W. Loss of suppressor T cells in adult NZB/NZW mice. $J$ Exp Med 1976; 144: 662-73.

12 Schrader J W, Nossal G J V. Effector cell blockade. A new mechanism of immune hyporeactivity induced by multivalent antigens. J Exp Med 1974; 139 : 1582-98.

13 Strelkauskas A J, Callery R T, Borel Y, Schlossman S F. Functional characteristics of human T-lymphocyte subsets identified by sera from patients with systemic lupus erythematosus. Clin Immunol Immunopathol 1979; 14: 47-55.

Correspondence to Dr R J Levinsky, Department of Immunology, Institute of Child Health, 30 Guilford Street, London WC1N 1EH.

Received 4 March 1980 